\title{
Influence of Surface Sealant on the Translucency of Composite Resin: Effect of Immersion Time and Immersion Media
}

Patrícia Petromilli Nordi Sasso Garcia*, Elídio Rodrigues Neto ${ }^{\mathrm{a}}$, Patrícia Aleixo dos Santos ${ }^{\mathrm{b}}$ Juliana Álvares Duarte Bonini Campos ${ }^{\mathrm{a}}$, Regina Guenka Palma Dibb ${ }^{\mathrm{c}}$

${ }^{a}$ Faculdade de Odontologia de Araraquara - UNESP, Rua Humaitá, 1680, 14801-903, Araraquara - SP, Brazil

${ }^{\mathrm{b}}$ Centro Universitário de Araraquara - UNIARA, Rua Carlos Gomes, 1338 4801-340, Araraquara - SP, Brazil

${ }^{\mathrm{c}}$ Faculdade de Odontologia de Ribeirão Preto - USP, Avenida do Café, s/n Campus Universitário Monte Alegre, 14040-904, Ribeirão Preto - SP, Brazil

Received: February 20, 2008; Revised June 6, 2008

This study evaluated the effect of surface sealant on the translucency of composite resin immersed in different solutions. The study involved the following materials: Charisma, Fortify and coffee, Coca-Cola ${ }^{\circledR}$, tea and artificial saliva as solutions. Sixty-four specimens $(n=8)$ were manufactured and immersed in artificial saliva at $37 \pm 1{ }^{\circ} \mathrm{C}$. Samples were immersed in the solutions for three times a day and re-immersed in artificial saliva until the translucency readings. The measurements were carried out at nine times: $\mathrm{T} 1-24$ hours after specimen preparation, T2 - 24 hours after immersion in the solutions, T3 - 48 hours and T4 to T9-7, 14, 21, 30, 60 and 90 days, respectively, after immersion. The translucency values were measured using a JOUAN device. The results were subjected to ANOVA and Tukey's test at 5\%. The surface sealant was not able to protect the composite resin against staining, the coffee showed the strongest staining action, followed by tea and regarding immersion time, a significant alteration was noted in the translucency of composite resin after 21 days.

Keywords: translucency, surface sealant, composite resin

\section{Introduction}

The development of composite resin has been contributed to the incorporation of aesthetic aspects in direct dental restorations, satisfying the desires of patients who expect dentists to provide restorations that not only restore the original function and shape of their teeth but also meet the same color, thus being clinically imperceptible ${ }^{1}$.

However, composite resin shows some undesirable characteristics, such as microleakage resultant from polymer shrinkage ${ }^{2}$, intrinsic discoloration and superficial staining, which may lead to color instability ${ }^{3}$. Moreover, composite resins undergo superficial and microstructural changes resultant from mastication and from finishing and polishing procedures ${ }^{4,5}$. These factors may lead to early staining of restorations.

The susceptibility to staining is related to various factors such as the type of organic matrix, particle size and its percentage in the material's composition, as well as the degree of polymerization, the time elapsed between the filling of the cavity and its finishing and polishing, the degree of smoothness, water sorption, type of staining agent and the length of time that this agent remains in contact with the material ${ }^{1}$. Other studies ${ }^{6,7,8}$ has described the continuous degradation undergone in aesthetic restorations, indicating that this kind of material stains easily and its color stability, surface hardness and wear strength may be affected.

Thus, when a composite resin is exposed to unfavorable factors such as the staining agents present in a patient's diet, the material's aesthetic appearance may be impaired. Therefore, to increase the durability of composite resin restoration and avoid the need of its replacement by reason of color alterations, professionals may offer possible solutions to prevent or reduce their staining.
A possible alternative to prevent or minimize color alterations of composite resin restorations is surface sealant, which composition contains Bis-GMA, UDMA and TEGDMA without filler particles ${ }^{5}$. This material has a low viscosity and high wettability ${ }^{9,10}$ and reduce some of the defects that restorations are subject, such as the marginal leakage ${ }^{1,9}$.In addition, this material provides restorations with a better superficial texture by penetrating into surface micro defects and increasing the smoothness of restored surfaces ${ }^{4}$.

The literature offers few studies about the effect of surface sealant on the staining of composite resins when subjected to different staining agents. It is therefore important to investigate whether the use of this material positively affects composite resin translucency, because translucency and color changes are interrelated and may influence the aesthetic results of a restoration ${ }^{11,12}$. Besides this, water sorption may cause color change and staining, which may promote weakening of filler/matrix bonding thus reducing the material's translucency and making stains difficult to remove $\mathrm{e}^{13,14}$.

In this way, the purpose of the present study was to assess the effect of surface sealant on the translucency of composite resin exposed to different type of solutions and periods of immersion.

\section{Experimental Proceedings}

\subsection{Experimental design}

The factors under study were: Surface sealant, at two levels (with and without sealant) and solutions at four levels (coffee, tea, Coke ${ }^{\circledR}$ and artificial saliva). The association between surface sealant and 
solutions resulted in 8 groups with 8 specimens each one, totaling 64 specimens. Specimens were randomly distributed using a random numbers table. Each specimen was chosen to compose experimental groups in the same way. Specimens had their translucency evaluated at nine immersion times (T1 - 24 hours of immersion in artificial saliva, T2 - after 24 hours of immersion in solution; T3 - after 48 hours of immersion; T4 - 7 days of immersion; T5 - after 14 days; T6 after 21 days; T7 - after 30 days; T8 - after 60 days and T9 - after 90 days). The quantitative response variable was the translucency values in percentage.

The composite resin used was Charisma (Kulzer), shade A3 and the surface sealant was Fortify (Table 1).

The following immersion solutions were employed:

- Artificial saliva - pH 7.0.

- Coffee (Brand: Serra da Grama - Torrefação e Moagem de Café Serra da Grama Ltda/ Batch: 21) - Immersion temperature: $70{ }^{\circ} \mathrm{C}-\mathrm{pH} 6.8$.

- Yerba Mate Tea (Brand: Matte Leão - Leão Junior SA/ Batch: C 060/06) - Immersion temperature: $70{ }^{\circ} \mathrm{C}-\mathrm{pH}$ 6.5; and

- $\mathrm{Coke}^{\circledR}$ - Immersion temperature: $10^{\circ} \mathrm{C}-\mathrm{pH} 2.62$.

Sixty-four samples were prepared in a $10 \mathrm{~mm}$ diameter, $2 \mathrm{~mm}$ thick stainless steel mold standing on a glass plate with a transparent polyester strip. These samples were prepared by inserting the composite resin into the mold cavity. To compact and take the excess of material out from the sample surfaces, the mold containing the resin was covered with another polyester strip and a glass plate placed on the top of it with a $4 \mathrm{~kg}$ weight for 30 seconds After that, the weight and the glass plate were removed and the composite resin was lightcured (KM 200R, DMC Equipment, a QTH unit, 450-600 mW/ $\mathrm{cm}^{2}$, $9 \mathrm{~mm}$ tip diameter) through the polymer strip for 40 seconds, and then, the resin specimen was removed from the matrix. (Figure 1)
The specimen bottom surface was identified with a bisturi blade. There was no polishing over the specimen surface because it was considered that the major superficial smoothness was obtained with the polyester strip ${ }^{15}$.

The 64 specimens were allocated into 8 groups: G1 to G4, corresponding to no treatment with surface sealant and G5 to G8, treatment with surface sealant.

The four groups (G1-G4) that were treated with no surface sealant were immersed in artificial saliva and stored at $37^{\circ} \mathrm{C} \pm 1$ until their translucency readings were done. In groups G5 to G8, the surface sealant Fortify was applied according to the manufacturer's instructions: surfaces were treated with $37 \%$ phosphoric acid gel (UNI - ETCH ${ }^{\circledR}$ ) for 15 seconds, rinsed with tap water for 20 seconds and dried for 20 seconds with absorbing paper. The sealant was applied over the entire surface of each specimen and then light-cured for 20 seconds.

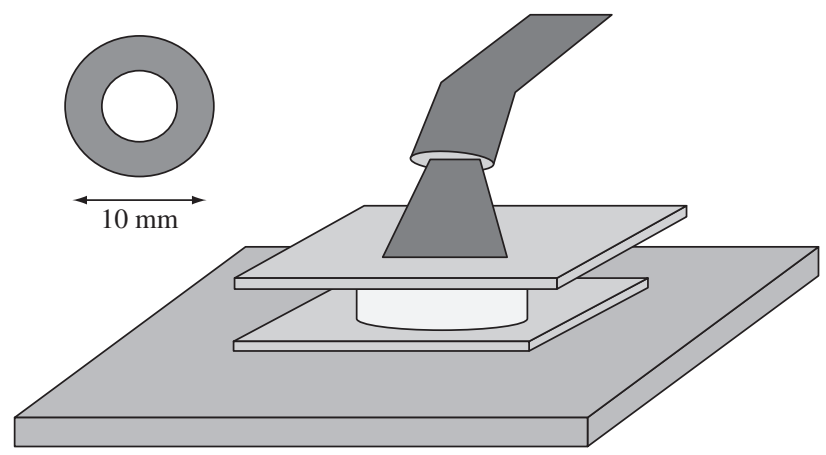

Figure 1. Photopolymerization of samples.

Table 1. Translucency (\%) mean and standard deviation for composite resin and $\mathrm{p}$-value $\left(\mathrm{p}_{1}\right.$ : sealant; $\mathrm{p}_{2}$ : solutions; $\mathrm{p}_{3}$ : interaction) resulting from two-way ANOVA.

\begin{tabular}{|c|c|c|c|c|c|c|c|c|}
\hline \multirow[b]{2}{*}{ Time } & \multicolumn{4}{|c|}{ Without Sealant } & \multicolumn{4}{|c|}{ With Sealant } \\
\hline & Saliva & Coke $^{\circledR}$ & Coffee & Tea & Saliva & Coke $^{\circledR}$ & Coffee & Tea \\
\hline \multirow{2}{*}{$\begin{array}{l}24 \text { hours } \\
\text { in saliva }\end{array}$} & $84.88 \pm 3.52$ & $84.38 \pm 1.92$ & $84.38 \pm 2.20$ & $84.50 \pm 0.93$ & $85.13 \pm 2.30$ & $84.38 \pm 1.92$ & $81.63 \pm 3.50$ & $83.00 \pm 2.27$ \\
\hline & $\mathrm{p}_{1}: 0.1188$ & $\mathrm{p}_{2}: 0.1321$ & $\mathrm{p}_{3}: 0.3457$ & - & - & - & - & - \\
\hline \multirow{2}{*}{$\begin{array}{l}24 \text { hours } \\
\text { after } \\
\text { immersion }\end{array}$} & $81.25 \pm 3.20$ & $84.25 \pm 2.38$ & $82.38 \pm 1.85$ & $81.00 \pm 2.93$ & $80.13 \pm 2.59$ & $79.25 \pm 3.01$ & $78.00 \pm 2.83$ & $81.13 \pm 3.64$ \\
\hline & $\mathrm{p}_{1}: 0.0005^{*}$ & $\mathrm{p}_{2}: 0.4284$ & $\mathrm{p}_{3}: 0.0313 *$ & - & - & - & - & - \\
\hline \multirow{2}{*}{$\begin{array}{l}48 \text { hours } \\
\text { after } \\
\text { immersion }\end{array}$} & $84.63 \pm 2.56$ & $82.50 \pm 4.21$ & $76.38 \pm 3.58$ & $78.38 \pm 2.00$ & $82.88 \pm 1.46$ & $83.00 \pm 2.14$ & $78.25 \pm 3.01$ & $79.75 \pm 2.60$ \\
\hline & $\mathrm{p}_{1}: 0.5914$ & $\mathrm{p}_{2}: 0.0001^{*}$ & $\mathrm{p}_{3}: 0.2489$ & - & - & - & - & - \\
\hline \multirow{2}{*}{$\begin{array}{l}7 \text { days of } \\
\text { immersion }\end{array}$} & $79.88 \pm 3.48$ & $79.50 \pm 3.25$ & $75.75 \pm 2.05$ & $78.13 \pm 3.48$ & $83.00 \pm 3.42$ & $83.25 \pm 1.75$ & $76.25 \pm 3.73$ & $79.88 \pm 3.40$ \\
\hline & $\mathrm{p}_{1}: 0.0039^{*}$ & $\mathrm{p}_{2}: 0.0001 *$ & $\mathrm{p}_{3}: 0.4317$ & - & - & - & - & - \\
\hline \multirow{2}{*}{$\begin{array}{l}14 \text { days of } \\
\text { immersion }\end{array}$} & $81.38 \pm 2.88$ & $80.38 \pm 2.45$ & $73.50 \pm 3.25$ & $76.50 \pm 3.55$ & $81.50 \pm 2.73$ & $83.38 \pm 2.33$ & $75.88 \pm 2.90$ & $78.88 \pm 3.23$ \\
\hline & $\mathrm{p}_{1}: 0.0093^{*}$ & $\mathrm{p}_{2}: 0.0001^{*}$ & $\mathrm{p}_{3}: 0.4926$ & - & - & - & - & - \\
\hline \multirow{2}{*}{$\begin{array}{l}21 \text { days of } \\
\text { immersion }\end{array}$} & $78.63 \pm 3.78$ & $78.13 \pm 2.70$ & $72.75 \pm 3.24$ & $76.00 \pm 2.51$ & $77.25 \pm 2.31$ & $78.63 \pm 2.13$ & $68.75 \pm 4.20$ & $73.25 \pm 3.01$ \\
\hline & $\mathrm{p}_{1}: 0.0169^{*}$ & $\mathrm{p}_{2}: 0.0001 *$ & $\mathrm{p}_{3}: 0.2415$ & - & - & - & - & - \\
\hline \multirow{2}{*}{$\begin{array}{l}30 \text { days of } \\
\text { immersion }\end{array}$} & $58.75 \pm 3.81$ & $56.75 \pm 2.96$ & $48.38 \pm 3.02$ & $54.50 \pm 3.74$ & $58.88 \pm 3.00$ & $58.38 \pm 1.19$ & $48.25 \pm 2.12$ & $53.50 \pm 3.66$ \\
\hline & $\mathrm{p}_{1}: 0.8419$ & $\mathrm{p}_{2}: 0.0001 *$ & $\mathrm{p}_{3}: 0.6728$ & - & - & - & - & - \\
\hline \multirow{2}{*}{$\begin{array}{l}60 \text { days of } \\
\text { immersion }\end{array}$} & $52.75 \pm 2.76$ & $52.63 \pm 2.50$ & $42.38 \pm 3.38$ & $50.13 \pm 2.90$ & $54.00 \pm 2.39$ & $53.88 \pm 1.46$ & $41.63 \pm 4.31$ & $48.00 \pm 2.39$ \\
\hline & $\mathrm{p}_{1}: 0.9205$ & $\mathrm{p}_{2}: 0.0001 *$ & $\mathrm{p}_{3}: 0.2616$ & - & - & - & - & - \\
\hline \multirow{2}{*}{$\begin{array}{l}90 \text { days of } \\
\text { immersion }\end{array}$} & $52.50 \pm 2.73$ & $50.50 \pm 2.83$ & $40.38 \pm 3.02$ & $48.25 \pm 3.11$ & $53.00 \pm 2.73$ & $52.88 \pm 2.10$ & $41.25 \pm 3.20$ & $48.25 \pm 2.96$ \\
\hline & $\mathrm{p}_{1}: 0.1897$ & $\mathrm{p}_{2}: 0.0001 *$ & $\mathrm{p}_{3}: 0.6572$ & - & - & - & - & - \\
\hline
\end{tabular}

*Statistically significant difference at $5 \%$. 
Immediately following application of the sealant, these groups were immersed in artificial saliva and stored at $37^{\circ} \mathrm{C} \pm 1$ for 24 hours, when the first reading of the specimens' translucency was done (T1).

After that, specimens were divided in 4 subgroups $(n=8)$ according to the solutions employed for specimen immersion (Table 1).

Translucency was measured after nine different periods of immersion: (T1) - after 24 hours in artificial saliva; (T2) - after 24 hours in different solutions; (T3) - after 48 hours of immersion; (T4) - 7 days of immersion; (T5) - 14 days; (T6) - 21 days; (T7) - 30 days; (T8) -60 days and (T9) - 90 days. It should be noted that immersions in the solutions (coffee, tea and Coke ${ }^{\circledR}$ ) were carried out three times a day for a 5-minute period each. These periods were defined by the own researchers, with the aim to get closer to a clinical approach. The specimens were kept immersed in artificial saliva between immersions. Before each reading, the specimens were rinsed in distilled water and dried with absorbent paper.

The translucency values (in percentage) were obtained using electrophoresis equipment JOUAN (Jouan - Paris - series $021 \mathrm{~A} /$ $\mathrm{n}^{\mathrm{o}} 10$ ), which measures the light radiation crossing the specimen. The light source excites a photoelectric cell, which in turn emits a signal to the galvanometer according to the degree of excitation from the light source, on a 0 to 100 scale, indicating the percentage of light that activated the photoelectric cell.

For each studied group, the mean and standard deviation were calculated. After analysing the normality and homocedasticity of sample distribuition, two-way analysis of variance (ANOVA) was used to each immersion time. Tukey's multiple comparisons test was used. Significance level was 5\%.

\section{Results}

The results obtained in this study are presented in Table 1 . The analysis of variance for the period " 24 hours in saliva" demonstrated that the translucency values presented no significant variability for each one of the factors isolately. In other terms, the translucency had a similar behavior when analyzed according to the presence of sealing and when analyzed according to the immersion media, with a non-significant interaction between them.

For the " 24 hours after immersion" period, it was observed that the factor sealant led to a significant variability in translucency, regardless of the tested medium. The translucency mean was lower when the sealant was used. When the factor "immersion media" was analyzed, it was verified non-significant variability, being the interaction sealant $\mathrm{X}$ medium significant.

After 48 hour of immersion, it was noted a significant variability only for the factor "immersion media", with coffee presenting the lower translucency mean than the other groups.

It was verified that after 7 days, the factor sealant and immersion media presented significant variability, being the interaction between factors non-significant. The translucency mean was significantly lower for the group without sealant. Regarding immersion media, groups immersed in saliva and Coke ${ }^{\circledR}$, with sealant, presented higher mean translucency values, with significant difference from the groups immersed in coffee and tea without sealant and than those immersed in coffee with sealant.

In 14 days period, both factors sealant and immersion media presented significant variability, being the interaction between factors non-significant. The translucency mean was significantly lower in groups without sealant. Groups immersed in coffee and tea presented lower mean translucency values.

After 21 days of immersion, sealant and immersion media presented significant variability, with the lowest translucency mean obtained when the sealant was used. Groups immersed in coffee and tea presented the lowest translucency mean.

From 30, 60 and 90 days, the translucency variability was nonsignificant for the factor "sealant" and for the interaction. The variability was only significant for the factor "immersion media", in which the coffee and tea presented lower translucency mean than the other groups, and coffee a lower translucency mean than tea.

All results obtained in function of time are shown in Figures 2 and 3.

\section{Discussion}

In this study, in which alterations in composite resin translucency were measured after immersion in different staining solutions that are commonly part of a patient's diet (Coke ${ }^{\circledR}$, coffee and tea), coffee was found to be the agent that caused the greatest changes in the material's translucency, followed by tea. Coke ${ }^{\circledR}$, on the other hand, showed a similar behavior to that of artificial saliva. This result can be described to the composite resins susceptibility to chemical erosion of the resin matrix, hydrolytic breakdown of filler particles and chemical degradation of silane agent, which are responsible process for discoloration and staining of the composite resin ${ }^{9,16,17}$. Therefore, to explain the present results, it is suggested that the greater susceptibility of the composite resin tested to staining by coffee may be due to the high temperature employed in the immersion cycle $\left( \pm 70{ }^{\circ} \mathrm{C}\right)$, which probably heated the surface of the material, thus

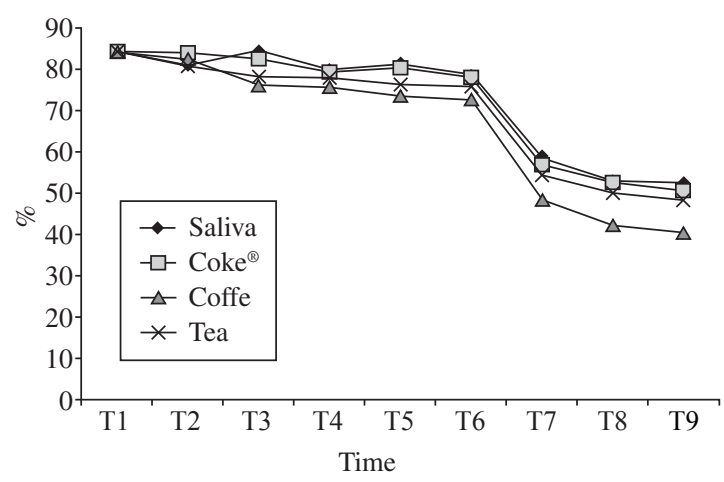

Figure 2. Translucency of composite resin without surface sealant in function of time.

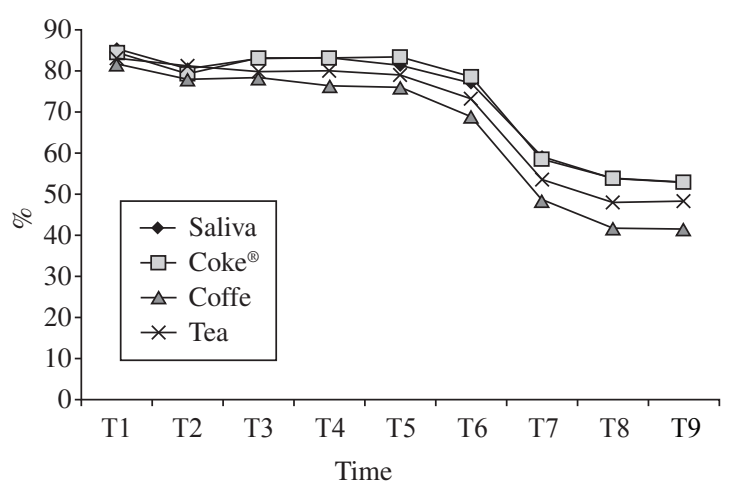

Figure 3. Translucency of composite resin with surface sealant in function of time. 
affecting the staining process. As this process appears to involve the degradation of the organic matrix, which facilitates pigmentation the material's aesthetic properties may be impaired. The same explanation is applied to the tea solution, which was also used at a high temperature. Besides this both tea and coffee contained yellow colorants with different polarities. Higher polarity components (like those in teas) were eluted first, and lower polarity components (like those in coffees) were eluted at a later time. Therefore, discoloration by tea might be due to absorption of polar colorants into the material surface. On the other hand, higher discoloration by coffee might be due to both adsorption and absorption of colorants. This absorption and penetration of colorants into the organic phase of the material were probably due to compatibility of the polymer phase with the yellow colorants of coffee $e^{18,19}$.

In an evaluation of the staining ability of four types of food that potentially stain composite resins, Chan et al. ${ }^{20}$ also found that coffee caused greater staining than tea and $\mathrm{Coke}^{\circledR}$. Other reports, e.g., Cooley et al. ${ }^{21}$ indicate that the greatest alterations in the translucence of materials occurred as a result of immersion in coffee.

In the present study, it was observed that the color of composite resin changes over time, regardless of factor sealant and immersion media, a fact that was corroborated by researchers ${ }^{3,22}$. (Figures 2 and 3) However, a separate analysis regarding the effect of time revealed that the translucency of the composite resin decreased to a greater extent after 21 days of immersion in solutions and not in the initial hours, and that in the later days of the test, i.e., after 60 days, the translucency remained constant. At literature, it is reported that staining reaches a peak at 7 days ${ }^{20,21}$, however, few number of studies has evaluated the staining for more than 3 weeks, what can difficult the comparison of the present results.

The discrepancy of this findings may be explained by the use of different methodologies, ${ }^{1,3,7,21}$ in which it may be observed that authors employed the immersion of specimens in the solution continually for a determined period, without removing any time from it. However, since since this study aimed to simulate a clinical situation, specimens were immersed in staining solutions for 5 minutes each time, three times a day, and were left in artificial saliva for the rest of the day (totaling 24 hours).

In relation to the surface sealant, it was noted that, both sealed and no-sealed specimens suffered alterations in translucency values at long-time. This can suggest that the sealant was not able to avoid composite resin staining. This fact probably occurred due to the fact that the surface sealant has no load in its composition, what makes its organic matrix more porous and susceptible to stain sorption ${ }^{23}$. Another possible hypothesis is that a polyester strip under a weight was used over the specimen during the polymerization process, in both sealed and no-sealed groups, with no further polishing, as defined in methodology, and so, the surface in the no-sealed groups were made in a similar way to those covered with the sealant, in which the organic matrix was directly exposed to immersion media.

To reduce the susceptibility of composite resin restorations to wear, marginal leakage and staining, some authors ${ }^{8,9,16,17,24}$ recommend the application of flowable resin on restoration surfaces. According to these authors, this material penetrates deep into microgaps and microdefects, promoting surface sealing, thereby protecting surfaces, reducing wear and increasing the longevity and performance of restorations.

On the other hand, the literature contains some reports, ${ }^{25,26}$ that disagree with these findings and contest the use of surface sealant and its advantages, alleging that the surface sealant could not prevent surface staining, as the pigmentation of the composite resins tested increased. Besides this, the authors affirm that its application offers few clinical advantages because the material is easily removed ${ }^{3}$.
Even though some literature researches point to the use of surface sealant to prevent restoration staining, the present study showed that this material did not present advantages in preventing the staining of tested composite resin.

\section{Conclusion}

According to the methodology employed in this study, it may be concluded that the surface sealant was not able to protect the composite resin against staining, the coffee was the staining solution that caused the greatest alteration in the translucency of the composite resin tested, followed by tea; the composite resin showed a significant alteration in translucency after 21 days of immersion in the solutions, and that the translucency remained stable between 60 and 90 days.

\section{References}

1. LeSage BP. Aesthetic composite restorations: a guide to direct placement. Dent.Clin. North Am. 2007; 51(2):359-378.

2. Rüttermann S, Krüger S, Raab WH, Janda R. Polymerization shrinkage and hygroscopic expansion of contemporary posterior resin-based filling materials - acomparative study. J. Dent. 2007; 35(10):806-813.

3. Wiltshire WA, Labuschagne PW. Staining of light cured aesthetic resin restorative materials by different staining media: an in vitro study. J. Dent. Assoc. in South Africa 1990; 45(12):561-565.

4. May Jr NK, Swift Jr EJ, Wilder Jr AD, Futrell SC. Effect of a surface sealant on microleakage of class V restorations. Amer. J. Dent. 1996; 9(3):133-136.

5. Ramos RP, Chimello DT, Chinelatti MA, Palma Dibb RG, Mondelli J. Effect of three surface sealants on marginal sealing of class $\mathrm{V}$ composite resin restorations. Oper. Dent. 2000; 25(6):448-452.

6. Asmussen E. Factors affecting the color stability of restorative resins. Acta Odontol. Scand. 1983; 41(1):11-18.

7. Iazzetti G, Burgess JO, Gardiner D, Ripps A. Color stability of fluoride containing restorative materials. Oper. Dent. 2000; 25(6):520-525.

8. Small BW. Direct posterior composite restorations - State of the art 1998. Gen. Dent. 1998; 46(1):26-32.

9. Dickinson GL, Leinfelder KF, Russel CM. Evaluation of wear by application of a surface sealant. J. Dent. Res. 1999; 67:362.

10. Leinfelder KF. Using composite resin as a posterior restorative material. J. Amer. Dent. Assoc. 1991; 122(4):65-70.

11. Kamishima N, Ikeda T, Sano H. Color and translucency of resin composites for layering techniques. Dent. Mater. J. 2005; 24(3):428-432.

12. Lee YK, Kim SH, Powers JM. Changes in translucency of resin composites after storage in salivary esterase. J. Esthet. Restorative Dent. 2005; 17(5):293-302.

13. Janda R, Roulet JF, Latta M, Rüttermann $\mathrm{S}$. Water sorption and solubility of contemporary resin-based filling materials. J. Biomed. Mater. Res. B Appl. Biomater. 2007; 82(2):545-551.

14. Martin N, Jedynaliewicz NM, Fisher AC. Hygroscopic expansion and solubility of composite restoratives. Dent. Mat. 2003; 19(2):77-89.

15. Bagheri R, Burrow MF, Tyas M. Influence of food-simulating solutions and surface finish on susceptibility to staining of aesthetic restorative materials. J. Dent. 2005; 33(5):389-398.

16. Dickinson GL, Leinfelder KF, Mazer RB, Russel CM. Effect of surface penetrating sealant on wear of posterior composite resins. J. Am. Dent. Assoc. 1990; 121(2):251-255.

17. Dickinson GL, Leinfelder KF. Assessing the long term effect of a surface penetrating sealant. J. Am. Dent. Assoc. 1993; 124(7):68-72.

18. Um CM, Ruyter IE. Staining of resin-based veneering materials with coffee and tea. Quintessence Int. 1991; 22(5):377-386.

19. Fujita M, Kawakami S, Noda M, Sano I. Color change of newly developed esthetic restorative material immersed in food-simulating solutions. Dent. Mater. J. 2006; 25(2):352-359. 
20. Chan KC, Fuller JL, Hormati AA. The ability of foods to stain two composite resins. J. Prosthet. Dent. 1980; 43(3):542-545.

21. Cooley RL, Barkmeier WW, Matis BA, Siok JF. Staining of posterior resin restorative materials. Quintessence Int. 1987; 18(12):882-887.

22. Buchalla W, Attin T, Hilgers RD, Hellwig E. The effect of water storage and light exposure on the color and translucence of a hybrid and a microfilled composite. J. Prosthet. Dent. 2002; 87(3):264-270.

23. Powers JM, Fan PL, Raptis CN. Color stability of new composite restorative materials under accelerated aging. J. Dent. Res. 1980; 59(12):2071-2074.
24. Ramos RP, Chinelatti MA, Chimello DT, Palma DIBB RG. Assessing microleakage in composite resin restorations rebounded with a surface sealant and three low-viscosity resin systems. Quintessence Int. 2002; 33(6):450-455.

25. Lee YK, Powers JM. Combined effects of staining substances on resin composites before and after surface sealant application. J. Mater. Sci.: Mater. Med. 2007; 18(5):685-691.

26. Lee YK, Lu H, Powers JM. Effect of surface sealant and staining on the fluorescence of resin composites. J. Prosthet. Dent. 2005; 93(3):260-266. 